\section{Proposição de um índice do enfrentamento governamental à violência intrafamiliar contra crianças e adolescentes}

\author{
Proposal of an index for government measures to \\ deal with domestic violence against children \\ and adolescents
}

\author{
Proposición de un índice de acción de gobierno \\ contra la violencia doméstica en niños \\ y adolescentes
}

Suely Deslandes 1

Corina Helena Figueira Mendes 1 Liana Wernersbach Pinto 2
1 Instituto Nacional de Saúde da Mulher, da Criança e do Adolescente Fernandes Figueira, Fundação Oswaldo Cruz, Rio de Janeiro, Brasil.

2 Escola Nacional de Saúde Pública Sergio Arouca

Fundação Oswaldo Cruz, Rio

de Janeiro, Brasil.

Correspondência

S. Deslandes

Departamento de Ensino,

Instituto Nacional de Saúde

da Mulher, da Criança e

do Adolescente Fernandes

Figueira, Fundação Oswaldo

Cruz.

Av. Rui Barbosa 716, Rio de Janeiro, RJ 22250-020, Brasil.

desland@iff.fiocruz.br

\begin{abstract}
The article discusses the development of the Index for Dealing with Family Violence to assess municipal strategies related to this violation of children's and adolescents' rights. Development of the index involved a preliminary analysis of indicators from previous studies and a technical expert group. Four indicators were selected: the existence of a municipal plan for dealing with violence against children and adolescents; the existence of an inter-sector flow for treating and following up on children and adolescents in situations of family violence; number of guardianship councils in relation to the municipality's population; and the existence of standardized instruments in municipal school, social work, and health systems for reporting situations of violence against children and adolescents. The databank from a previous study was used in an exercise to apply the indicator in four Brazilian state capitals. The indicator can serve as a tool for monitoring and mobilizing efforts to implement measures for dealing with family violence.
\end{abstract}

Child Advocacy; Violence; Indicators

\section{Resumo}

O artigo apresenta o processo de construção do Índice de Enfrentamento de Violência Intrafamiliar (IEVI), cujo objetivo é avaliar estratégias da gestão municipal em face dessa violação de direitos infantojuvenis. Sua formulação envolveu análise preliminar de indicadores de estudos anteriores e técnica grupo nominal com especialistas. Foram selecionados quatro indicadores: existência de Plano Municipal de Enfrentamento das Violências contra Crianças e Adolescentes; existência de fluxo intersetorial para atendimento e acompanhamento de crianças e adolescentes em situação de violência intrafamiliar e suas famílias; taxa de Conselhos Tutelares por habitantes do município; e existência, nas redes municipais de educação, assistência social e saúde, de instrumentos padronizados para notificação/comunicação das situações de violência contra crianças e adolescentes. Com base em banco de dados de estudo anterior, foi realizado o exercício de aplicação em quatro capitais brasileiras. O IEVI constitui uma ferramenta para monitorar e mobilizar esforços para a implantação de ações de enfrentamento da violência.

Defesa da Criança e do Adolescente;

Violência; Indicadores 


\section{Introdução}

A análise e o monitoramento de um problema social ou das formas de intervenção a ele dirigidas envolvem, usualmente, processos dinâmicos e não lineares, trazendo para quem os analisa o desafio de traduzir realidades complexas sob a forma de definições sintéticas, claras e objetivas. Tais ferramentas de análise são denominadas indicadores e se destinam a aferir dimensões tanto individuais, como coletivas, servindo de medida ou forma de apreciação, direta ou indireta, de um evento, situação, conceito, processo ou condição, e constituindo seus meios de verificação. Indicadores são recursos metodológicos que, ancorados em base empírica, traduzem aspecto da realidade social ou as mudanças que estão se efetivando 1,2,3.

Raramente um único indicador é suficientemente abrangente e inclusivo para traduzir determinado problema social ou os efeitos dos projetos e ações que visam a sua mudança. Um conjunto de indicadores, voltado para um tema ou aspecto específico da realidade (também designado sistema de indicadores), busca minimizar as dificuldades que são intrínsecas ao exercício de redução da realidade aos seus aspectos mais substantivos, significativos e estratégicos.

A construção de um sistema de indicadores envolve pelo menos quatro etapas 2: (1) definição operacional do conceito abstrato ou da temática a que se refere o sistema; (2) especificação de descrição de suas dimensões, das formas de interpretar tal tema, tornando claro seu foco, permitindo uma análise da coerência em face dos indicadores designados; (3) busca de estatísticas públicas, bancos de dados e informações disponíveis para a aplicação dos referidos indicadores; (4) aplicação dos dados ao cálculo dos indicadores.

Também para minimizar os limites do emprego isolado de um indicador, são criados índices, que são parâmetros capazes de revelar o estado de um sistema multidimensional ou um fenômeno, sendo, geralmente, compostos por um grupo de indicadores 4 . Um índice sintetiza um conjunto de aspectos sob análise, permitindo a comparação e o escalonamento de resultados entre diversas regiões ou mesmo países.

Alguns índices são bastante conhecidos e utilizados em larga escala, como o Índice de Gini, criado em 1910 para aferir o grau de desigualdade de renda entre os mais pobres e os mais ricos. Outro exemplo conhecido é o Índice de Desenvolvimento Humano (IDH), criado em 1997 para medir o progresso social e humano de um país, considerando-se três dimensões básicas: renda, educação e saúde 5 .
O desafio posto para a criação de índices é a especificidade, ou seja, precisa reunir uma composição de indicadores que, uma vez associados, sejam adequados para aferir exatamente o foco de interesse, traduzindo as variações que se deseja analisar. As maiores críticas aos índices são sua pouca transparência (compreensão metodológica restrita a técnicos da área e dificuldade de manuseio); a estrita dependência à disponibilidade e atualização periódica dos dados que compõem cada indicador agregado; e a possível incapacidade de refletir as questões mais relevantes para a análise do problema 2,6 .

O emprego dos indicadores, isolados ou num sistema, ou agregados sob a forma de índice, não pode e nem deve estar dissociado da análise dos contextos sociopolíticos em que os processos sob avaliação ou monitoramento ocorreram, tampouco do cotejamento das ações dos atores e das condições estruturais em que se deram. Os índices não são ferramentas neutras, pois representam escolhas científicas e ideológicas, sendo influenciados por visões históricas de relevância do que e como avaliar 7 .

Por fim, os indicadores devem ser aplicados segundo um plano de avaliação, que organicamente os produz, seleciona e hierarquiza, atribuindo-lhes valores em relação aos padrões de desempenho daquilo que a estratégia avaliada pretende alcançar. Eles invocam o estreito diálogo com os modelos teóricos das estratégias e respectivas propostas avaliativas.

Indicadores ou índices dependem da qualidade de sistemas distintos de informação, de fontes secundárias de dados, das interpretações que fazem os aplicadores de seus propósitos e termos. Constituem ferramentas úteis, porém devem ser constantemente avaliados e criticados enquanto dispositivos auxiliares na importante $\mathrm{e}$ singular tarefa de emitir valor sobre o mérito de programas e estratégias.

A violência é, há mais de duas décadas, reconhecida pela Organização Mundial de Saúde e pelo Ministério de Saúde brasileiro como grave problema de saúde pública, bem como constitui uma questão da pauta dos movimentos globais por saúde e da agenda de saúde global 8,9,10. Nesse contexto, crianças e adolescentes são o segmento etário mais vulnerável a todas as formas de violência, especialmente no âmbito das relações interpessoais e comunitárias, sendo a violência familiar a manifestação mais prevalente contra este grupo 11 .

Destarte, se há exemplos de índices para o monitoramento social da evolução e tendências da violência contra a população infantojuvenil (Índice de Vulnerabilidade Juvenil, Índice de Homicídios na Adolescência e Índice de Bem- 
Estar Juvenil), pouco se criou para a análise das formas de enfrentamento dessa situação. Os escassos estudos encontrados tratam de indicadores voltados apenas para análise dos serviços de atendimento 13,14 .

Entendemos enfrentamento como o conjunto de estratégias integradas, articuladas e contínuas para lidar com o fenômeno da violência. São intervenções que têm como objetivo um ciclo de trabalho que inclui: (1) a promoção de comportamentos protetores e prevenção; (2) a atenção àqueles em situação de violência; (3) o fortalecimento das instituições e dos mecanismos de garantia de direitos dessas pessoas; (4) a valorização da notificação e do registro desses eventos; (5) o investimento nas instituições e nas formas de responsabilizar aqueles que agrediram crianças e adolescentes. É diferente, portanto, da perspectiva de "combate", que prioriza a responsabilização criminal dos autores 15 .

Neste artigo, apresentamos uma proposta de índice que visa a analisar o enfrentamento da violência familiar contra crianças e adolescentes por parte das gestões municipais. Apresentamos o índice de enfrentamento da violência intrafamiliar (IEVI) e discutimos suas potencialidades para o controle social da atuação governamental diante do problema e para a advocacy do desenvolvimento de ações. Apontamos seus limites a partir do exercício de aplicação em quatro capitais brasileiras (Belém, Campo Grande, Fortaleza e Porto Alegre) e sugerimos estratégias para utilização desse índice com vistas à mobilização social para o enfrentamento dessa forma de violência.

\section{Notas metodológicas do percurso de construção do IEVI}

Os índices utilizados para a elaboração do IEVI fazem parte de um sistema originalmente composto por 41 indicadores, construídos em 2007, em parceria com o Fundo das Nações Unidas para a Infância (Unicef), para apoiar o monitoramento e análise avaliativa da atuação dos governos municipais de centros urbanos no enfrentamento da violência intrafamiliar e exploração sexual de crianças e adolescentes. Como já descrito em trabalho anterior 16, esses indicadores foram elaborados com base em métodos participativos (técnicas Delphi e grupo nominal), envolvendo sucessivas consultas a especialistas de todo o país. A base de elaboração foi um conjunto amplo de normativas nacionais (políticas, planos e normas técnicas) que tratam sobre o papel dos municípios no enfrentamento da violência. Os indicadores foram agrupados em cinco eixos ou dimensões de enfrentamento: (1) promoção de relações familiares e comunitárias protetoras e prevenção da(s) violência(s); (2) atenção a crianças e adolescentes em situação de violência intrafamiliar e exploração sexual e aos seus familiares; (3) garantia de direitos de crianças e adolescentes nessas situações de violências; (4) qualificação do registro e notificação dos eventos; (5) responsabilização legal dos autores dessas violências.

Após aplicação em seis municípios de grande porte populacional, foi realizada uma revisão do sistema de indicadores, tendo como base os critérios de validade, confiabilidade, sensibilidade, comunicabilidade, relevância social e factibilidade de obtenção de dados. Chegamos a um acervo de 32 indicadores, já apresentados em publicação anterior 12, que constituiu a base para a seleção do IEVI.

Nova parceria com o Unicef foi empreendida em 2013, cuja demanda era a de criação de um índice voltado aos gestores e demais operadores do Sistema de Garantia de Direitos da Criança e do Adolescente. Tal índice deveria permitir a mobilização social em torno das responsabilidades e potencialidades de atuação dos governos municipais para o enfrentamento da violência contra crianças e adolescentes.

A seleção dos indicadores para compor o IEVI se deu por meio da utilização da técnica grupo nominal, envolvendo oito especialistas convidados (conselheiros de direitos e pesquisadores do tema) 12 . A técnica de grupo nominal é uma técnica grupal para a tomada de decisões acerca de tema para o qual não haja consenso. Reúne um número reduzido de especialistas em encontro presencial mediado por um pesquisador. Geralmente a sessão é estruturada considerando-se as seguintes etapas: apresentação da questão nominal, redação individualizada das opiniões e respostas de cada participante, exposição de cada opinião, debate, votação, discussão da classificação global e reclassificação coletiva a partir de nova rodada de debate 17. A questão disparadora proposta foi a seguinte: Considerando sua relevância e facilidade de acesso aos dados, quais destes indicadores melhor sintetizam o enfrentamento da violência intrafamiliar por parte da gestão municipal? O eixo de responsabilização dos autores foi retirado por não fazer parte das responsabilidades municipais.

Os critérios de seleção dos indicadores foram: apresentar relevância para a atuação governamental municipal diante de cada eixo de enfrentamento da violência (intra)familiar (promoção e prevenção, atenção, fortalecimento do sistema de garantia de direitos e registro); ser constituído por dados acessíveis e de fácil manejo, permitindo que agentes do sistema de garantia de 
direitos, mesmo sem formação técnica, pudessem utilizar o índice; possibilitar aplicação sucessiva ao longo do tempo a baixo custo.

Após a seleção dos indicadores, foi realizada nova fase de consulta a outros especialistas, envolvendo sete profissionais do Unicef: cinco técnicos da área central de avaliação e monitoramento e dois responsáveis pelas plataformas de intervenção para a defesa de direitos de crianças e adolescentes nos centros urbanos do país. Esse painel de especialistas foi realizado em três sessões não estruturadas, a partir de debate livre, com intervalos de uma semana, por meio de Skype e registrados por escrito. Considerando os mesmos critérios de seleção dos indicadores, esses especialistas discutiram a proposta produzida pela técnica de grupo nominal, apresentando sugestões para a normalização das formas de cálculo (expressão para simplificação da fórmula, ajuste da taxa empregada) e para escalonar os resultados (utilização do parâmetro do IDH).

Posteriormente, utilizaram-se informações para exemplificar a aplicação do IEVI, as quais foram extraídas do banco de dados do estudo Avaliação das Estratégias Governamentais $\mathrm{Mu}$ nicipais no Enfrentamento da Violência Sexual e Exploração Sexual de Crianças e Adolescentes em Quatro Capitais Brasileiras (Belém - Pará, Campo Grande - Mato Grosso do Sul, Fortaleza - Ceará e Porto Alegre - Rio Grande do Sul), que foi aprovado por Comitê de Ética em Pesquisa (CAAE: 00786612.2.0000.5269). Esse projeto não foi desenhado objetivando a aplicação do IEVI, mas serviu como banco de consulta de dados. $\mathrm{O}$ estudo realizou análise diagnóstica situacional da atuação de governos municipais no enfrentamento da exploração sexual e demais violências contra crianças e adolescentes, utilizando-se do citado sistema dos 32 indicadores. As referidas cidades foram escolhidas por terem apresentado expressivo número de notificações de violências ao sistema de denúncias do Disque 100, nas suas respectivas regiões. As informações foram coletadas em 2012, referentes ao biênio 2010-2011, a partir de 84 depoimentos de gestores locais de todas as secretarias municipais que apresentavam ações diretas com o segmento infantojuvenil; de conselheiros de direitos e de conselheiros tutelares (29 entrevistados em Porto Alegre, 19 em Fortaleza, 14 em Campo Grande e 22 em Belém). As informações colhidas de entrevistas semiestruturadas foram devidamente comprovadas por documentação.

\section{Índice de enfrentamento da violência intrafamiliar (IEVI)}

O primeiro indicador que compõe o IEVI é existência de plano municipal de enfrentamento das violências contra crianças e adolescentes, o qual revela o engajamento da gestão em ações planejadas, sistemáticas e intersetoriais que visem à prevenção, à atenção as crianças e adolescentes em situações de violências e à restauração dos seus direitos violados. Um plano municipal com essa finalidade está previsto em distintas políticas públicas nacionais de enfrentamento das violências, como a Política Nacional de Promoção da Saúde 18, a Política Nacional de Redução de Morbimortalidade por Acidentes e Violências 19 e a Portaria MS/GM no 936 20, que dispõe sobre a estrutura da Rede Nacional de Prevenção da Violência e Promoção da Saúde, além da implantação de Núcleos de Prevenção da Violência em Estados e Municípios.

O Plano Nacional de Promoção, Proteção e Defesa do Direito de Crianças e Adolescentes à Convivência Familiar e Comunitária 21 também prevê a elaboração de planos municipais e estaduais, a fim de garantir o direito de crianças e de adolescentes à convivência nessas esferas de relações, especialmente daqueles em situação de vulnerabilidade.

No que se refere especificamente ao enfrentamento da violência sexual, o Plano Nacional de Enfrentamento da Violência Sexual Infantojuvenil 22 sugere que cada município desenvolva seu plano e contemple seis diretrizes orientadoras: (1) análise da situação; (2) mobilização e articulação; (3) defesa e responsabilização; (4) atendimento; (5) prevenção; e (6) protagonismo juvenil. A metodologia empregada pela Secretaria Especial de Direitos Humanos da Presidência da República para a implantação destas diretrizes estimula a criação de planos operativos locais com tal perspectiva.

Sendo assim, a existência de qualquer plano municipal abrangendo o enfrentamento das distintas formas de violência, independentemente de sua origem, já configura resposta positiva. Todavia, a existência de mais de um plano só deverá ser contabilizada no cálculo do IEVI somente uma vez. Este indicador apresenta, portanto, variáveis de resposta dicotômicas (sim ou não).

O segundo indicador selecionado para compor o IEVI, existência de fluxo intersetorial para atendimento e acompanhamento de crianças e adolescentes em situação de violência intrafamiliar e suas famílias, trata do eixo da atenção, tendo como principal parâmetro avaliativo a oferta de cuidados integrados e integrais tanto a crianças e adolescentes em situação de violência in- 
trafamiliar, quanto a seus familiares. Esse indicador avalia a organização da rede de atendimento, assim como a efetiva pactuação dos diferentes setores na construção de um fluxo que otimize o atendimento, garanta a proteção, acolha as diferentes demandas e evite a revitimização. Sua resposta, também dicotômica, se positiva, deve aferir um ponto no cálculo do IEVI.

A formulação desse indicador se baseou na diretriz da atenção interdisciplinar às pessoas em situações de violências, que consta em quase todas as políticas públicas sobre o tema. Essa orientação está postulada textualmente na Política Nacional de Redução de Morbimortalidade por Acidentes e Violências 19, que preconiza a estruturação e a organização da rede de serviços do Sistema Único de Saúde (SUS) para que se identifiquem as vítimas de violências e acidentes e se acolham suas demandas, prestando-lhes atendimento digno, de qualidade e resolutivo, desde o primeiro nível de atenção.

O Sistema Único de Assistência Social (SUAS) também estabelece como princípio organizativo a intersetorialidade, bem como atribui aos entes federados a responsabilidade de "definir os fluxos de referência e contra-referência do atendimento nos seus serviços socioassistenciais" (Art. 12, Inc. $\mathrm{XX)}$ e ainda de "promover a articulação intersetorial do SUAS com as demais políticas do Sistema de Garantia de Direitos" (Idem, Inc. XXV) 23 (p. 17-18).

O Estatuto da Criança e do Adolescente (ECA) diz no Art. 86 que "a política de atendimento dos direitos da criança e do adolescente far-se-á através de um conjunto articulado de ações governamentais e não-governamentais da União, dos estados, distrito federal e municípios" 24 , que se traduz no Sistema de Garantia de Direitos da Criança e do Adolescente. Por sua vez, o Plano Decenal de Diretos Humanos da Criança e do Adolescente preconiza que cada município formule diretrizes e parâmetros para estruturação de redes integradas de atenção a crianças e adolescentes em situação de violências, com base nos princípios de celeridade, humanização e continuidade no atendimento 25 .

Algumas iniciativas para a definição de fluxos do atendimento em rede já foram realizadas, dentre as quais se destaca a da Associação Brasileira de Magistrados, Promotores de Justiça e Defensores Públicos, em parceria com a Childhood Brasil e diversos atores, para a construção dos fluxos operacionais de atendimento de crianças e adolescentes nas situações de abuso, exploração sexual, HIV/AIDS e gravidez na adolescência 26 .

Sabe-se que a desarticulação e as lacunas do Sistema de Garantia de Direitos da Criança e do
Adolescente têm repercussão direta na capacidade de restituir direitos violados 27 . A definição de um fluxo sistematizado de atendimento a criança e adolescente em situação de violência e a suas famílias mostra-se bastante sensível para aferir a maturidade da cooperação intersetorial de um município. Reflete a capacidade de diálogo e de cooperação de um conjunto de atores e agências públicas em torno de objetivos comuns de promoção de cuidados e restituição de direitos de crianças e adolescentes. Sabe-se, ainda, que não basta existir um fluxo meramente burocrático ou idealizado; mais que isso, um fluxo deve orientar a ação concreta e cotidiana dos atores da rede, de acordo com seus papéis e atribuições, bem como permitir visualizar deficiências e demandas não atendidas. Exige, também, atualizações periódicas, dado que a rede é sempre dinâmica, possui considerável rotatividade de profissionais e que a complexidade das situações das famílias institui sempre novas necessidades.

O terceiro indicador a compor o IEVI, taxa de Conselho Tutelar por habitantes do município, vincula-se ao eixo que trata do apoio da gestão municipal para o fortalecimento do Sistema de Garantia de Direitos da Criança e do Adolescente diante de situações de violência intrafamiliar e exploração sexual de crianças e adolescentes.

O Conselho Tutelar é importante protagonista dentre as instituições que compõem o Sistema de Garantia de Direitos da Criança e do Adolescente, sendo obrigação do governo municipal garantir número adequado de Conselhos Tutelares e meios para seu pleno funcionamento. Ao Conselho Tutelar é outorgado um lugar estratégico no fluxo de atendimento à criança e ao adolescente em situação de violência. Todas as denúncias e notificações de fatos de violência infantojuvenil devem convergir para o Conselho Tutelar; este, por sua vez, tem a atribuição de avaliar a demanda de violação do direito e aplicar as medidas de proteção à criança e ao adolescente (Art. 101, ECA), bem como aos seus pais e responsáveis (Art. 129, ECA), com a finalidade de restituição do direito violado ou preservação do direito ameaçado. Cabe ainda ao Conselho Tutelar encaminhar ao judiciário, quando for o caso de responsabilização da família, do Estado ou da sociedade 24 .

Encontramos, em planos e resoluções do Conselho Nacional dos Direitos da Criança e do Adolescente (CONANDA), várias orientações que visam ao fortalecimento do Conselho Tutelar para o efetivo cumprimento de suas atribuições. Reconhecendo a dificuldade de cobertura e atendimento das demandas, o CONANDA recomenda como parâmetro que 28 : 
“Art. 3o Em cada Município e no Distrito Federal haverá, no mínimo, um Conselho Tutelar como órgão da administração pública local.

$\$ 1$ o Para assegurar a equidade de acesso, caberá aos Municípios e ao Distrito Federal criar e manter Conselhos Tutelares, observada, preferencialmente, a proporção mínima de um Conselho para cada 100 mil habitantes (grifo nosso)".

Nesse sentido, observar a proporcionalidade do número de Conselhos Tutelares em relação ao número de habitantes no seu território de abrangência é uma das condições para maior efetividade da intervenção desse órgão em casos de violação dos direitos infantojuvenis.

Ao argumento de que este seria um indicador elementar, contrapunha-se o fato de que a cobertura adequada nos Conselhos Tutelares, nos centros urbanos, ainda se revela muito aquém da demanda. Certamente, as condições de trabalho, de suporte e de qualificação dos conselheiros tutelares são elementos estratégicos e estão longe de apresentar bons padrões, repercutindo na qualidade do atendimento prestado 29 . Considerando-se o território nacional, a existência dos Conselhos Tutelares na proporcionalidade adequada é um desafio a ser superado.

Segundo sugestão dos especialistas, levandose em conta que poucos municípios de grande porte populacional apresentam a proporção adequada de Conselhos Tutelares, foi feito um levantamento das taxas de todas as capitais brasileiras a fim de se chegar ao cálculo de uma taxa ajustada à realidade nacional. Na obtenção da taxa ajustada, inicialmente calculou-se a taxa para cada um dos municípios dividindo-se o número de Conselhos Tutelares pelo tamanho populacional. De posse das taxas, foram calculados os percentis 75, 80, 85 e 90 da distribuição. Escolheu-se como ponto de corte o percentil 90, o qual equivaleu a uma taxa de 0,65. Este valor foi, então, usado como ponderação no cálculo das taxas ajustadas.

A formulação do indicador se apresenta da seguinte forma:

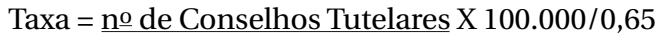

População total de habitantes

Para o cálculo, se o valor encontrado for superior a 1, será contabilizada a nota máxima neste quesito (1).

Finalmente, o quarto indicador do IEVI é a existência, nas redes municipais de educação, assistência social e saúde, de instrumentos padronizados para notificação/comunicação das situações de violências contra crianças e adolescentes. Esse indicador corresponde ao eixo referente a notificação e valorização do registro.
A legislação brasileira prevê, como dever de todos os cidadãos e prática obrigatória para médicos e professores, a obrigatoriedade da comunicação ao Conselho Tutelar de casos suspeitos ou confirmados de maus-tratos contra crianças e adolescentes. Entende-se que essa prática deva estender-se também aos demais profissionais das áreas de saúde, educação e assistência social 24. A notificação é essencial no enfrentamento das violências contra crianças e adolescentes e no processo de restauração de seus direitos. Além de possibilitar a interrupção das violências e desencadear medidas de proteção e assistência a crianças e adolescentes, assim como a seus familiares, oferece, ainda, informações para avaliar a situação local e dimensionar a necessidade de intervenções em determinado território 30 .

Nas políticas nacionais, encontramos diretrizes, objetivos e propostas que justificam a escolha deste indicador para compor o IEVI. O Plano Decenal corrobora tal orientação quando, no Objetivo Estratégico 5.1, dispõe: “Articular e aprimorar os mecanismos de denúncia, notificação e investigação de violações dos direitos de crianças e adolescentes" 25 (p. 38). Encontramos, também, no Programa Nacional de Direitos Humanos, o objetivo estratégico de "implantar sistema nacional de registro de ocorrência de violência escolar, incluindo as práticas de violência gratuita e reiterada entre estudantes (bullying), adotando formulário unificado de registro a ser utilizado por todas as escolas" 31 (p. 94-95). Igualmente, na Política Nacional de Redução de Morbimortalidade por Acidentes e Violências, a diretriz da qualificação do registro consta como base da atuação do setor Saúde 19

O setor Saúde tem desempenhado papel fundamental na construção de informações sobre os acidentes e violências. Em 2001, o Ministério da Saúde dispôs sobre a obrigatoriedade da notificação de casos de maus-tratos contra crianças e adolescentes atendidos no SUS 32 . Ao final da década, foi instituída a notificação compulsória de todas as formas de violências interpessoais. O Sistema de Informação de Agravos de Notificação (SINAN) 33 consolida a notificação dos casos de violências pelas unidades de saúde e se destaca como um sistema estruturado. O Ministério da Saúde desenvolve ações desde a capacitação para o preenchimento das fichas, processamento dos dados, análise, até a disseminação da informação. Todavia, sabe-se que o SINAN encontra-se em fase de implantação desigual nos estados, e muitos municípios ainda não alimentam o sistema ${ }^{30}$. Por outro lado, as estratégias de implementação de um sistema de informação e de qualificação dos registros das violências contra crianças e adolescentes nos âmbitos da 
educação e da assistência social ainda são escassas e configuram-se como mais um desafio a ser superado 34 .

Entretanto, reconhecemos iniciativas que apontam a viabilidade da adoção de instrumentos de notificação, unificados ou não, como um dos passos iniciais e essenciais para a institucionalização de um sistema de informações sobre violência. A adoção e a utilização de ficha padronizada pelas unidades da rede pública constituem ações de grande relevância para que as situações de violências saiam da invisibilidade, para que possam ser mensuradas em sua magnitude e caracterizadas em sua dinâmica e distribuição.

A atribuição de valor do quarto indicador é feita mediante o total da soma de secretarias com instrumento padronizado (um ponto para cada resposta positiva) dividido por 3 . Foram consideradas as secretarias cujas unidades têm maior contato com a população infantojuvenil: Educação, Saúde e Assistência Social.

Finalmente, os enunciados dos indicadores do IEVI se apresentam da seguinte forma:

$\mathrm{I}_{1}=$ existência de Plano Municipal de Enfrentamento das Violências contra Crianças e Adolescentes.

$\mathrm{I}_{2}=$ existência de fluxo intersetorial para atendimento e acompanhamento de crianças e adolescentes em situação de violência intrafamiliar e suas famílias.

$\mathrm{I}_{3}=$ taxa de Conselhos Tutelares por habitantes do município.

$\mathrm{I}_{4}=$ existência, nas redes municipais de educação, assistência social e saúde, de instrumentos padronizados para notificação/comunicação das situações de violências contra crianças e adolescentes.

Os quatro indicadores terão seus resultados dentro do intervalo 0-1. O resultado final do IEVI será dado pela média aritmética dos valores obtidos para os indicadores que compõem o índice:

O IEVI será dado por:

$I E V I=\frac{I_{1}+I_{2}+I_{3}+I_{4}}{4}$

IEVI $=\frac{\sum_{k=1}^{4} I_{k}}{4}$

Após consulta à literatura e debate entre os especialistas, houve consenso de que não havia evidências de que um indicador fosse mais estratégico ou produzisse resultados mais eficazes no enfrentamento da violência (intra)familiar do que outro. Logo, a elaboração da fórmula do IEVI considerou a hipótese de que todos os indicadores selecionados tivessem a mesma importância. Assim, todos os indicadores têm peso igual. Quanto à forma de agregar os indicadores, a literatura mostra que a utilização de agregação linear pode ser empregada sempre que os indicadores forem comparáveis, ou seja, estejam todos em uma escala intervalar 35 .

Uma vez concluído o cálculo do IEVI, os municípios deverão ser classificados da seguinte forma: 0,0 a 0,49 (baixo enfrentamento à violência familiar); 0,50 a 0,69 (médio enfrentamento); 0,70 a 0,79 (alto enfrentamento); 0,80 a 1,0 (muito alto enfrentamento). A categorização utilizada adotou os mesmos critérios de faixas de valores do IDH desenvolvido pelo Programa das Nações Unidas para o Desenvolvimento.

\section{Exemplos de aplicação do IEVI}

Com base em consulta aos bancos de dados de pesquisa realizada recentemente nas quatro capitais brasileiras já referidas 36 , trazemos exemplos da aplicação da Tabela 1.

Campo Grande e Fortaleza estariam, no período retratado, na posição de nível muito alto de enfrentamento à violência intrafamiliar contra crianças e adolescentes. Porto Alegre e Belém, em situação de médio enfrentamento.

\section{Discussão}

Como qualquer índice, o IEVI constitui uma redução de realidades complexas a um conjunto restrito de indicadores 37 . Mesmo que se parta do pressuposto de que as estratégias retratadas no IEVI refletem um nível de amadurecimento do trabalho da gestão municipal e a ação coletiva de vários atores do Sistema de Garantia de Direitos da Criança e do Adolescente, ainda assim o índice não permite aferir a qualidade e a efetividade das ações realizadas.

Igualmente a qualquer instrumento de cotejamento, o IEVI é delimitado temporalmente. Os dados apresentados na aplicação do índice referem-se aos anos de 2010-2011, sendo, por isso, datados em sua capacidade de aferição. Porto Alegre, por exemplo, em 2013, homologou um fluxo de atendimento intersetorial, incluindo parcerias com Ministério Público, secretarias municipais e Delegacia da Criança e Adolescente Vítima. Com essa resposta positiva, o mesmo índice aumentaria para 0,92. Dessa forma, o índice proposto não pode ser visto como um dispositivo classificatório dos municípios, mas um disparador para o debate e a realização de ações públicas de enfrentamento da violência.

Como pontos fortes da proposta, consideramos que, por suas características, o IEVI possui boa comunicabilidade (grau de entendimento 
Tabela 1

Exercício de aplicação do IEVI nas cidades de Belém (Pará), Fortaleza (Ceará), Porto Alegre (Rio Grande do Sul) e Campo Grande (Mato Grosso do Sul), Brasil, 2010-2011.

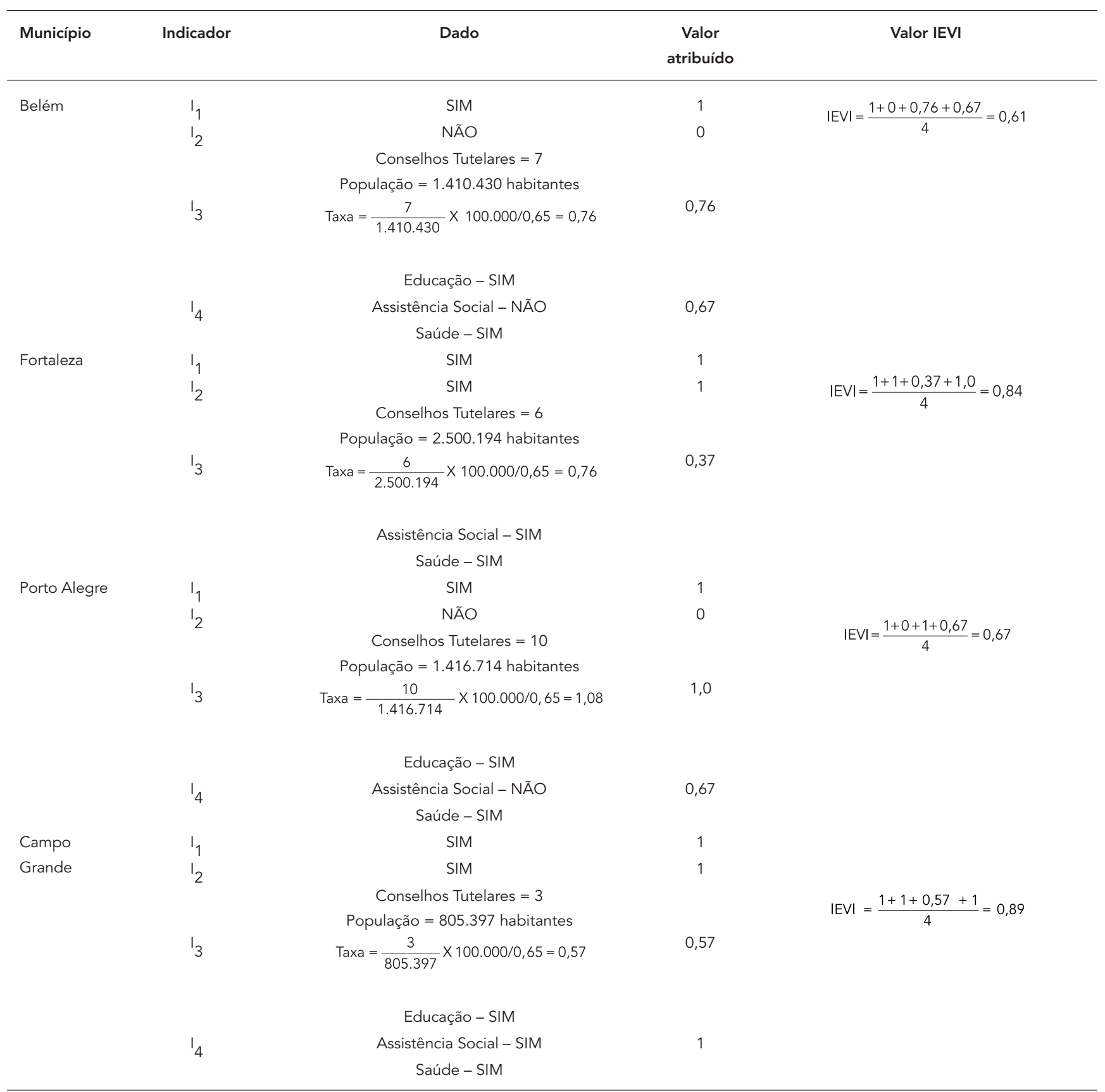

IEVI: Índice de Enfrentamento de Violência Intrafamiliar.

$\mathrm{I}_{1}$ : Existência de Plano Municipal de Enfrentamento das Violências contra Crianças e Adolescentes; $\mathrm{I}_{2}$ : Existência de fluxo intersetorial para atendimento e acompanhamento de crianças e adolescentes em situação de violência intrafamiliar e suas famílias; $I_{3}$ : Taxa de Conselhos Tutelares por habitantes do município; $I_{4}$ : Existência, nas redes municipais de educação, assistência social e saúde, de instrumentos padronizados para notificação/comunicação das situações de violência contra crianças e adolescentes. 
acessível), viabilidade de periodicidade (capacidade de ser atualizado periodicamente a custos baixos), excelente visibilidade (possibilidade de acesso disseminado aos dados, permitindo o controle social das instituições e das políticas públicas) e permite a construção de séries históricas, normalizadas sob a mesma forma de medida, para possibilitar comparações no tempo 1,2,3, ou mesmo entre municípios.

O IEVI apresenta, ainda, boa factibilidade de obtenção, isto é, boa possibilidade de execução, relativa facilidade de disponibilidade de dados e baixos custos para obtê-los. Além disso, seus indicadores podem refletir os avanços obtidos ao longo de um mandato de gestão governamental, o que o torna atraente por medir efeitos a médio e curto prazos 38 .

Defendemos que o IEVI, como expressão sintética, pode ser entendido como uma "mensagem forte" 38 (p. 82) aos gestores, para adoção de uma cultura de compromisso com os direitos de crianças e adolescentes e de enfrentamento das violências; constitui, também, ferramenta importante de controle social sobre a atuação dos governos municipais. Ademais, pode ser utilizado para fortalecer o advocacy 39 em torno do princípio de que crianças e adolescentes têm o direito de viver em famílias sem violência e que os governos municipais têm responsabilidades na garantia de tais condições. Portanto, o IEVI tem o potencial de comunicar ideias e agregar forças sociais para essa pauta de mobilização, ajudando a pressionar a favor da implantação de políticas já existentes sobre o tema, da formulação de ações e da alocação de recursos.

O texto apresenta um exercício a partir de banco de dados existentes, funcionando apenas como um teste das expressões de cálculo. Entendemos que algumas etapas e ações na fase de aplicação são recomendáveis para que o IEVI cumpra o papel de mobilização pretendido 39 : (1) envolvimento de grupos sociais, de operadores de direitos e de mídias apropriadas para a divulgação da iniciativa; (2) desenvolvimento de parcerias com os governos municipais, Conselho Municipal de Direitos de Crianças e Adolescentes (CMDCA) e Conselho Tutelar para o planejamento das formas de levantamento e divulgação dos dados; (3) criação de um grupo de trabalho para a aplicação do índice, envolvendo representantes do governo municipal, das organizações não governamentais atuantes na defesa de direitos de crianças e adolescentes, além do CMDCA; e (4) divulgação pública dos resultados e pactuação de ações visando às mudanças necessárias.

Certamente, o acúmulo de experiências de aplicação do IEVI permitirá um refinamento de sua expressão, possibilitando flexibilidade maior de sua pontuação. A atribuição de fracionamento de pontos para processos em fase de implantação poderá ser uma via alternativa para os limites impostos pelas variáveis dicótomas.

A proposição do IEVI levou em conta a importância de fortalecer a parceria entre a academia e o Sistema de Garantia de Diretos da Criança e do Adolescente, favorecendo a formulação de instrumentos que avaliem e permitam o monitoramento de forma simples, capazes de serem incorporados aos processos de trabalho e gestão de municípios, em diferentes momentos de amadurecimento, na implementação de políticas voltadas para os direitos humanos de crianças e adolescentes.

\section{Resumen}

Se presenta la construcción del Índice de Lucha contra de Violencia Intrafamiliar (IEVI) por sus siglas en portugués) para evaluar las estrategias de gestión de los municipios, frente a la violación de los derechos de niños y adolescentes. Su formulación involucró el análisis de indicadores utilizados en investigaciones previas y la técnica de un grupo nominal con expertos que seleccionaron cuatro: existencia de un plan municipal de lucha contra la violencia ejercida en niños y adolescentes; existencia de flujo intersectorial para el tratamiento y el seguimiento de niños y adolescentes en situación de violencia intrafamiliar y sus familias; tasa de consejos de protección por habitantes del municipio y, la existencia en redes municipales de educación, asistencia social y salud de instrumentos estandarizados para la comunicación de la violencia. A partir de la base de datos del estudio anterior, se realizaron ejercicios de aplicación en cuatro capitales brasileñas. El IEVI es una herramienta para monitorear y movilizar esfuerzos para la implementación de acciones en contra de la violencia.

Defensa del Niño; Violencia; Indicadores 


\section{Colaboradores}

S. Deslandes coordenou a pesquisa, produziu e analisou os dados, além de colaborar na redação do artigo. C. H. F. Mendes e L. W. Pinto colaboraram na produção e análise dos dados e na redação do artigo.

\section{Agradecimentos}

Agradecemos os apoios do Unicef e do CNPq.

\section{Referências}

1. Minayo MCS. Construção de indicadores qualitativos para avaliação de mudanças. Rev Bras Educ Méd 2009; 33 Suppl 1:83-91.

2. Jannuzzi PM. Indicadores sociais no Brasil. 3a Ed. Campinas: Editora Alínea; 2006.

3. Niremberg O, Brawerman JRV. Evaluar para la transformación. Buenos Aires: Paidós; 2005.

4. Sich R, Agostinho F, Ortega E, Romero A. Índices versus indicadores: precisões conceituais na discussão da sustentabilidade de países. Ambiente \& Sociedade 2007; 10:137-48.

5. Rocha S. Pobreza no Brasil: afinal, de que se trata? Rio de Janeiro: Editora FGV; 2003.

6. Jannuzzi PM. Indicadores sociais na formulação e avaliação de políticas públicas. Rev Bras Adm Pública 2002; 36:51-72.
7. Assis SG, Deslandes SF, Minayo MCS, Santos NC. Definição de objetivos e construção de indicadores visando à triangulação. In: Minayo MCS, Assis SG, Souza ER, organizadores. Avaliação por triangulação de métodos. Rio de Janeiro: Editora Fiocruz; 2005. p. 105-32.

8. Minayo MCS. A inclusão da violência na agenda da saúde: trajetória histórica. Ciênc Saúde Coletiva 2006; 11:1259-67.

9. Kickbusch I, Berger C. Diplomacia da saúde global. Revista Eletrônica de Comunicação Informação \& Inovação em Saúde 2010; 4:19-24.

10. Sodre F. A agenda global dos movimentos sociais. Ciênc Saúde Coletiva 2011; 6:1781-91. 
11. Organização Mundial da Saúde. Relatório Mundial sobre violência e saúde. Genebra: Organização Mundial da Saúde; 2002.

12. Deslandes SF, Mendes CHF, Luz ES. Análise de desempenho de sistema de indicadores para o enfrentamento da violência intrafamiliar e exploração sexual de crianças e adolescentes. Ciênc Saúde Coletiva 2014; 19:865-74.

13. Ferreira AL, Souza ER. Análise de indicadores de avaliação do atendimento a crianças e adolescentes em situação de violência. Cad Saúde Pública 2008; 24:28-38.

14. Viviescas-Vargas DP, Idrovo AJ, López-López E, Uicab-Pool G, Herrera-Trujillo M, Balam-Gómez M, et al. Cobertura efectiva del manejo de la violencia contra mujeres en municipios Mexicanos: límites de la métrica. Rev Esc Enferm USP 2013; 47:781-7.

15. Secretaria Nacional de Enfrentamento à Violência contra as Mulheres; Secretaria de Políticas para as Mulheres. Política nacional de enfrentamento à violência contra as mulheres. Brasília: Ideal Gráfica e Editora; 2011.

16. Deslandes SF, Mendes CHF, Campos, DS. Use of the Nominal Group Technique and the Delphi Method to draw up evaluation indicators for strategies to deal with violence against children and adolescents in Brazil. Rev Bras Saúde Matern Infant 2010; 10 Suppl 1:s29-37.

17. Pope C, Mays N. Usando o Delfos e a técnica grupo nominal na pesquisa em serviços de saúde. In: Pope C, Mays N, organizadores. Pesquisa qualitativa na atenção à saúde. 2a Ed. Porto Alegre: Editora Artmed; 2005. p. 51-61.

18. Ministério da Saúde. Portaria no 687 de 2006. Aprova a Política Nacional de Promoção de Saúde. Diário Oficial da União 2006; 31 mar.

19. Ministério da Saúde. Portaria no 737 de 2001. Aprova a Política Nacional de Redução da Morbimortalidade por acidentes e violências. Diário Oficial da União 2001; 18 mai.

20. Ministério da Saúde. Portaria no 936 de 2004. Dispõe sobre a estruturação da Rede Nacional de Prevenção da Violência e Promoção da Saúde e a Implantação e Implementação de Núcleos de Prevenção à Violência em Estados e Municípios. Diário Oficial da União 2004; 20 mai.

21. Conselho Nacional dos Direitos da Criança e do Adolescente; Conselho Nacional de Assistência Social, Ministério do Desenvolvimento Social e Combate à Fome. Plano Nacional de Promoção, Proteção e Defesa do Direito de Crianças e Adolescentes à Convivência Familiar e Comunitária. Brasília: Ministério do Desenvolvimento Social e Combate à Fome; 2006.

22. Secretaria de Direitos Humanos. Plano Nacional de Enfrentamento da Violência Sexual Infantojuvenil. Uma política em movimento. Relatório do monitoramento 2003-2004. Brasília: Comitê Nacional de Enfrentamento à Violência Sexual contra Crianças e Adolescentes, Secretaria Nacional de Promoção dos Direitos da Criança e do Adolescente; Secretaria de Direitos Humanos, Presidência da República. Brasília; 2006.
23. Secretaria Nacional de Assistência Social, Ministério do Desenvolvimento Social e Combate à Fome. Norma Operacional Básica do Sistema Único de Assistência Social. Brasília: Ministério do Desenvolvimento Social e Combate à Fome; 2012.

24. Brasil. Lei no 8.069 de 13 de julho de 1990. Dispõe sobre o Estatuto da Criança e do Adolescente e dá outras providências. Diário Oficial da União; 16 jul.

25. Secretaria de Direitos Humanos. Plano Decenal de Direitos Humanos da Criança e do Adolescente; 2011 http://www.obscriancaeadolescente.gov.br/ index.php?option=com_phocadownload\&view=file\&id=102:plano-decenal-2011\&Itemid=133 (acessado em 16/Jan/2015).

26. Associação Brasileira de Magistrados, Promotores de Justiça e Defensores Públicos da Infância e da Juventude. Cadernos de fluxos operacionais sistêmicos. Proteção integral e atuação em rede na garantia dos direitos de crianças e adolescentes. São Paulo: Associação Brasileira de Magistrados, Promotores de Justiça e Defensores Públicos; 2010.

27 Ungaretti MA. Fluxos operacionais sistêmicos: instrumento para aprimoramento do Sistema de Garantia dos Direitos no contexto dos direitos humanos. In: Ungaretti MA, organizador. Criança e adolescente. Direitos, sexualidades e reprodução. São Paulo: Associação Brasileira de Magistrados, Promotores de Justiça e Defensores Públicos da Infância e da Juventude; Childhood Brasil; 2010. p. 101-28.

28. Conselho Nacional dos Direitos da Criança e do Adolescente. Resolução no 139 de 17 de março de 2010. Dispõe sobre os parâmetros para a criação e funcionamento dos Conselhos Tutelares no Brasil, e dá outras providências. Diário Oficial da União 2011; 18 mar.

29. Mendes AG, Matos MC. Uma agenda para os conselhos tutelares. In: Sales MA, Matos MC, Leal MC, organizadores. Política social, família e juventude: uma questão de direitos. São Paulo: Editora Cortez; 2004. p. 208-43.

30. Assis SG, Avanci, JQ, Pesce RP, Pires TO, Gomes DL. Notificações de violência doméstica, sexual e outras violências contra crianças no Brasil. Ciênc Saúde Coletiva 2012; 17:2305-17.

31. Secretaria de Direitos Humanos. Programa Nacional de Direitos Humanos (PnDH-3). Brasília: Liberdade de Expressão, 2010.

32. Ministério da Saúde. Portaria no 1.968 de 25 de outubro de 2001. Dispõe sobre a notificação, às autoridades competentes, de casos de suspeita ou de confirmação de maus-tratos contra criança e adolescente atendidos no Sistema Único de Saúde. Diário Oficial da União 2001; 26 out.

33. Ministério da Saúde. Portaria no 104 de 25 de janeiro de 2011. Define as terminologias adotadas em legislação nacional, conforme o disposto no Regulamento Sanitário Internacional 2005 (RSI 2005), a relação de doenças, agravos e eventos em saúde pública de notificação compulsória em todo o território nacional e estabelece fluxo, critérios, responsabilidades e atribuições aos profissionais e serviços de saúde. Diário Oficial da União 2011; 26 jan. 
34. Faleiros JM, Matias ASA, Bazon MR. Violência contra crianças na cidade de Ribeirão Preto, São Paulo, Brasil: a prevalência dos maus-tratos calculada com base em informações do setor educacional. Cad Saúde Pública 2009; 25:337-48.

35. Nardo M, Saisana M, Saltelli1 A, Tarantola S, Hoffman A, Giovannini E. OECD handbook on constructing composite indicators: methodology and user guide. Paris: Organisation for Economic Cooperation and Development; 2005. (OECD Statistics Working Paper 2005/3)

36. Deslandes SF. Relatório de Pesquisa: avaliação das estratégias governamentais municipais no enfrentamento da violência sexual e exploração sexual de crianças e adolescentes em quatro capitais brasileiras [CD-ROM]. Versão 3.0. Rio de Janeiro: Fundação Oswaldo Cruz; 2014.
37. Arregui CC. O debate sobre a produção de indicadores sociais alternativos: demandas por novas formas de quantificação. Serv Soc Soc 2012; (111):529-54.

38. Torres HG, Ferreira MP, Dini NP. Indicadores sociais: por que construir novos indicadores como o IPRS. São Paulo Perspect 2003; 17:80-90.

39. United Nations Children's Fund. Advocacy toolkit. A guide to influencing decisions that improve children's lives. New York: United Nations Children's Fund; 2010

Recebido em 02/Jun/2014

Versão final reapresentada em 09/Jan/2015

Aprovado em 02/Mar/2015 